\title{
Alumina-zirconia coatings obtained by suspension plasma spraying from highly concentrated aqueous suspensions
}

\author{
P. Carpio ${ }^{1,2}$, M. D. Salvador ${ }^{1}$, A. Borrell ${ }^{1}$, E. Sánchez ${ }^{2}$, R. Moreno ${ }^{3}$ \\ ${ }^{1}$ Instituto de Tecnología de Materiales (ITM), Universitat Politècnica de València \\ (UPV), Camino de Vera, s/n, 46022 Valencia, Spain \\ ${ }^{2}$ Instituto de Tecnología Cerámica (ITC), Universitat Jaume I (UJI), Av. Sos Baynat s/n, \\ 12006 Castellón, Spain \\ ${ }^{3}$ Instituto de Cerámica y Vidrio (ICV), Consejo Superior de Investigaciones Científicas \\ (CSIC), Kelsen 5, E-28049 Madrid, Spain
}

Corresponding autor: Pablo Carpio

Email: pabcarco@upv.es

\begin{abstract}
Suspension plasma spraying (SPS) deposition represents an innovative technique to produce coatings that exhibit improved properties. However, the key to obtain coatings with superior functional properties relies on the investigation of the suspensions as starting materials. For this reason, the present work deals with the suspension preparation for SPS process and its influence on the resulting coatings.

Laboratory-prepared 60/40 wt\% alumina-zirconia suspensions were concentrated to avoid energy loss and were then successfully deposited by SPS technique. The liquid used was water instead of ethanol due to economical, environmental and safety reasons. The preparation of the suspension plays an important role in SPS process since stable and well-dispersed water suspensions are difficult to obtain. For this reason, colloidal behaviour characterisation of the starting particles as well as rheological optimisation of the feedstock suspensions were addressed in this research.

Suspensions with different solid loadings (up to 30 vol.\% or $72 \mathrm{wt} \%$ ) were deposited using several spraying distances. All coatings displayed a bimodal microstructure consisting in partially melted zones surrounded by a fully melted matrix. $\alpha-\mathrm{Al}_{2} \mathrm{O}_{3}$ and t'- $\mathrm{ZrO}_{2}$ constituted the main crystalline phases, but differences in the microstructure and properties of the coatings were observed. From these results, some relations between starting suspension and spraying parameters with coating characteristics were found. Thus the optimal spraying distance becomes shorter when the suspension solid loading increases.
\end{abstract}

Keywords: plasma spraying, suspensions, thermal barrier coatings (TBC), alumina, zirconia 


\section{Introduction}

Yttria-partially stabilised zirconia (YSZ) are currently used for the fabrication of thermal barrier coatings (TBC) because of their low thermal conductivity and good mechanical properties at high temperature. However, YSZ undergoes phase degradation after long in-service times at relatively high temperatures, limiting the operational temperature of the coatings and their lifetime [1]. One possible solution addressed in previous works consists in adding alumina to zirconia stabilized with different yttria contents. This addition enhances the thermodynamic stabilization and improves the mechanical properties and thermal fatigue $[2,3]$.

Atmospheric plasma spraying (APS) represents one of the most suitable techniques used to obtain TBCs as a consequence of the good mechanical and thermal performance of the coatings obtained as well as an easy scaling-up of the technique [4]. It consists in the injection of a powder into a plasma flow where this powder is later subjected to melting and then accelerated until it impacts on the substrate. The main problem of the APS technique lies in the starting powder preparation because the feedstock must meet several requirements (an agglomerate apparent specific mass higher than $1700 \mathrm{~kg} / \mathrm{m}^{3}$ or a mean agglomerate size coarser than $60 \mu \mathrm{m}$ ). Furthermore, their production is costly $[5,6]$. One alternative to conventional APS technique, known as suspension plasma spraying (SPS), consists in spraying fine-particle suspensions instead of coarse powders. SPS coatings display smaller microstructural defects, which can lead to improved properties. In the case of TBCs, SPS technique also allows the reduction of the thermal conductivity due to a higher porosity made up of finer voids $[7,8]$.

The SPS process has been intensively studied in the last years. However, more research in this technique is necessary to tackle its main problems. One of them deals with the preparation of suitable feedstock suspensions so that they could be industrially scalable. Suspensions must be well-dispersed and stable in order to avoid particle agglomeration or sedimentation. Besides suspension viscosity cannot be too high for the suspension to properly flow through the injector. However it is interesting to note that solids loading of the suspension should be as high as possible so as to improve the deposition efficiency $[9,10]$.

Concerning the suspension liquid the use of water instead of organic solvents would be preferred due to economical, environmental, and safety reasons. Nevertheless, most of the previous research about SPS deposition employs organic liquids (ethanol) due to their lower vaporisation enthalpy. Furthermore, when water is used suspension stabilisation becomes more difficult and therefore, a previous colloidal behaviour characterisation should be a mandate in these cases.

On the other hand, suspension solid loading is usually low for reducing the power necessary to evaporate the solvent and to melt the solid [5]. However, Vicent et al. demonstrated that power requirements become lower when solid loading is increased in the case of water suspension, in opposition to what occurs in ethanol suspensions [11]. Therefore, high solid loading suspension deposition is convenient in terms of energy and efficiency, so that thicker coatings can develop with less spraying passes. However increasing solids content leads to higher viscosity suspensions as a consequence of the exponential growth of viscosity with volume fraction of solids [12]. Moreover, some authors point out that coating properties are strongly dependent on suspension 
characteristics, finding a relationship between solid loading and coating properties [1315]. Because of the above achieving all feedstock suspension requirements (no agglomeration, long-term stability and low viscosity) with high solid content suspensions as well as assessing the impact of suspension characteristics on coating microstructure and properties is certainly a challenge.

Apart from increasing the solid loading, the possibility of depositing an eutectic composition can also reduce the power requirements. In the case of the alumina/zirconia system, the eutectic composition is $58 / 42 \mathrm{wt} \%$. However, no equilibrium phases form in plasma processes owing to rapid melting inside the plasma plume as well as fast cooling on the substrate surface. Some authors have found a pseudo-eutectic point for a composition of $60 / 40 \mathrm{wt} \%$ to $\mathrm{Al}_{2} \mathrm{O}_{3} / \mathrm{ZrO}_{2}$, where the temperature to melt the solid inside the plasma plume is minimum $[3,16]$. Hence, a reduction of plasma enthalpy requirements is achieved by depositing this pseudo-eutectic composition. In previous works, $\mathrm{Al}_{2} \mathrm{O}_{3} / \mathrm{ZrO}_{2}$ coatings by plasma spraying from powders were successfully developed $[2,16]$. However, $\mathrm{Al}_{2} \mathrm{O}_{3} / \mathrm{ZrO}_{2}$ coatings by SPS have been less addressed. Besides when SPS coatings were researched the corresponding feedstocks suspensions were too diluted (30 wt.\%) for industrial scale $[3,17]$. For this reason, the aim of the present work is to develop a thermal barrier coating by SPS technique from aqueous $\mathrm{Al}_{2} \mathrm{O}_{3} / \mathrm{YSZ}$ suspensions with low power consumption by using concentrated suspensions of an eutectic composition.

\section{Experimental}

\subsection{Materials}

Two commercial submicron-sized powders were used as starting materials: (1) an $\alpha$ $\mathrm{Al}_{2} \mathrm{O}_{3}$ (Condea-Ceralox HPA-0.5, Sasol, USA) with a mean particle size of $0.35 \mu \mathrm{m}$ and a specific surface area of $9.5 \mathrm{~m}^{2} / \mathrm{g}$; and (2) a yttria-stabilised zirconia (TZ-3YS, Tosoh Co., Japan) with a $\mathrm{Y}_{2} \mathrm{O}_{3}$ ratio of 3 mol\% to stabilise the tetragonal phase, mean particle size of $0.4 \mu \mathrm{m}$ and specific surface area of $6.8 \mathrm{~m}^{2} / \mathrm{g}$. In addition, a commercial salt (DURAMAX $^{\mathrm{TM}}$ D-3005, Rohm \& Haas/Dow Chemicals, USA) of polyacrylic acidbased polyelectrolyte (PAA), with $35 \mathrm{wt} \%$ active matter, was used as dispersant in order to achieve the colloidal stability of the powders in water. This dispersant has been used in other previous works with alumina and zirconia powders [18,19].

\subsection{Suspension preparation and characterisation}

Suspensions were prepared adding first $60 \mathrm{wt} \% \mathrm{Al}_{2} \mathrm{O}_{3}$ particles and then $40 \mathrm{wt} \% \mathrm{Y}$-TZP particles to the dispersing medium (optimal quantity of dispersant into water). In order to breakdown any present agglomerates, the suspensions were dispersed with a sonication probe (UP 400S, Dr Hielscher GmbH, Germany). Suspensions with different solid loadings were prepared.

The colloidal stability of $\mathrm{Al}_{2} \mathrm{O}_{3}$ and Y-TZP powders in aqueous suspensions was studied by zeta potential measurements as a function of dispersant content and $\mathrm{pH}$. The equipment used to measure the zeta potential is based on the laser Doppler velocimetry technique (Zetasizer NanoZS, Malvern, UK). In order to perform the measurements, diluted suspensions with a $0.01 \%$ solid content and $0.01 \mathrm{M} \mathrm{KCl}$ as electrolyte were 
prepared. The $\mathrm{pH}$ values were determined with a $\mathrm{pH}$-meter (Titrino DMS 716, Metrohm, Switzerland) and they were adjusted with $\mathrm{HCl}$ and $\mathrm{KOH}$ solutions. Zeta potential measurements are suitable to establish the optimal amount of dispersant in the suspensions $[12,18]$.

The rheological behaviour of all suspensions was determined using a rotational rheometer (Bohlin CVO 120, Malvern Instruments, Great Britain) operating at controlled shear rate (CR) by loading the shear rate from 0 to $1000 \mathrm{~s}^{-1}$ in $5 \mathrm{~min}$, maintaining it at $1000 \mathrm{~s}^{-1}$ for $1 \mathrm{~min}$ and downloading from 1000 to $0 \mathrm{~s}^{-1}$ in $5 \mathrm{~min}$. The measurements were carried out at $25{ }^{\circ} \mathrm{C}$ using a double-plate system. The ageing effect of the suspensions was also assessed by determining the rheological behaviour at 1 and 7 days after suspension preparation. During this time, suspensions were maintained agitated in a low speed orbital shaker [20].

\subsection{Coating deposition}

Coatings were obtained by suspension plasma spraying technique (SPS). A plasma torch (F4-MB, Oerlikon Metco, Germany) operated by an industrial robot (IRB 1400, $\mathrm{ABB}$, Switzerland) was adapted in order to spray suspensions by mechanical injection assisted by air pressure with a maximum pressure of 6 bar. More details about SPS adaptation have been described in a previous work [21]. In this study, suspensions inside a vessel were agitated by a magnetic stirrer to avoid possible sedimentation and a viscosity rise in the case of thixotropic suspensions. Furthermore, two injectors with different diameters (150 and $200 \mu \mathrm{m}$ ) were utilised depending on the suspension viscosity. Suspensions with different solid loadings (from 10 vol.\% up to 30 vol.\%) were deposited using different spraying distances in order to study the influence of starting suspension characteristics, as well as spraying parameters.

Suspensions were deposited on an austenitic cylindrical stainless steel (AISI 304) substrate with a diameter of $25 \mathrm{~mm}$. Prior to deposition, the substrates were grit-blasted with corundum at a pressure of 4.2 bar and cleaned with ethanol to remove any remaining dust or grease from the surface. The substrates were preheated between 300 ${ }^{\circ} \mathrm{C}$ and $350{ }^{\circ} \mathrm{C}$ with the plasma torch to enhance coating adhesion. The spraying parameters used in this work are specified in table 1.

Table 1. Main spraying parameters of $\mathrm{Al}_{2} \mathrm{O}_{3} / \mathrm{Y}-\mathrm{TZP}$ coatings

\begin{tabular}{|c|c|c|c|}
\hline & \multicolumn{3}{|c|}{ Suspension solid loading (vol.\%) } \\
\hline & 10 & 20 & 30 \\
\hline Ar flow rate (slpm*) & \multicolumn{3}{|c|}{37} \\
\hline $\mathrm{H}_{2}$ flow rate (slpm) & \multicolumn{3}{|c|}{8} \\
\hline Intensity (A) & \multicolumn{3}{|c|}{700} \\
\hline Linear speed (m/s) & \multicolumn{3}{|c|}{1} \\
\hline Feedstock flow rate $(\mathrm{ml} / \mathrm{min})$ & \multicolumn{3}{|c|}{27} \\
\hline Number of spraying passes & \multicolumn{3}{|c|}{4} \\
\hline Injector diameter (mm) & & & 0.2 \\
\hline Spraying distance (mm) & & & $50 ; 60$ \\
\hline
\end{tabular}

*slpm: standard litre per minute 


\subsection{Coating characterisation}

First, polished coating cross-section microstructures were observed by FEG-SEM (S4800, Hitachi, Japan). Coating thickness was measured, as well as porosity and cracks quantified, by image analysis from 10 micrographs at 1000x magnification. Elemental analysis was performed by SEM using energy dispersive X-ray analysis (EDX) and element mappings were obtained. Coating crystalline phases were identified by X-ray diffraction (XRD D8 Advance, BrukerAXS, Germany) with $\mathrm{Cu} \mathrm{K} \alpha$ radiation $(\lambda=1.54183 \AA$ ) . Finally, Vickers hardness was determined with a microhardness tester (LECO M400, Leco Co., USA), performing ten indentations on each sample (50 g for $10 \mathrm{~s})$.

\section{$\underline{\text { 3. Results and discussion }}$}

\section{$\underline{\text { 3.1. Suspension preparation }}$}

In previous works, the colloidal stabilisation of $\mathrm{Al}_{2} \mathrm{O}_{3}$ and $\mathrm{Y}$-TZP powders was addressed and colloidal stabilisation curves at different PAA contents were determined $[18,19]$. Such curves permit to establish=the maximum amount of PAA which is available to adsorb onto the particles. This value was $0.3 \mathrm{wt} \%$ for $\mathrm{Al}_{2} \mathrm{O}_{3}$ and $0.5 \mathrm{wt} \%$ for Y-TZP particles. Fig. 1 shows the evolution of zeta potential of $\mathrm{Al}_{2} \mathrm{O}_{3}$ and Y-TZP powders as a function of $\mathrm{pH}$ with and without PAA. The isoelectric point (IEP) of these powders using those concentrations of dispersant shifts down from 9.2 to 3.8 for $\mathrm{Al}_{2} \mathrm{O}_{3}$ and from 5.9 to 2.4 for Y-TZP. Hence, PAA disperses both powders by an electrosteric mechanism where particles are negatively charged at neutral $\mathrm{pH}$. Thus, heterocoagulation mechanism in which particles with different signs are attracted is not expected to occur between $\mathrm{Al}_{2} \mathrm{O}_{3}$ and $\mathrm{Y}$-TZP particles as they all have the same electric charge sign.

Once colloidal characterisation of the diluted suspension was performed, higher concentration suspensions at different solid loadings were prepared. Fig. 2 shows the flow curves of $\mathrm{Al}_{2} \mathrm{O}_{3}-\mathrm{Y}-\mathrm{TZP}$ suspensions prepared at solid contents of 10 vol.\% ( 34 wt\%), 15 vol.\% ( 45 wt\%), 20 vol.\% ( 54 wt\%) and 30 vol.\% ( 66 wt\%). All suspensions displayed a low viscosity although viscosity increased exponentially with solid concentration, as expected. This tendency is usually observable in concentrated ceramic suspensions [12]. The shear rate inside the injector is very high $\left(>1000 \mathrm{~s}^{-1}\right)$ because of the very small injector diameter. For this reason, the viscosity at very high shear rate $(\mu)$ was estimated using the Cross model fit:

$$
\frac{\eta_{0}-\eta}{\eta-\eta_{\propto}}=(K \cdot \dot{\gamma})^{m}
$$

where $\eta$ is the suspension viscosity (in $\mathrm{Pa} \cdot \mathrm{s}$ ) at $\dot{\gamma}$ shear rate (in $\mathrm{s}^{-1}$ ), $\eta_{0}$ is the suspension viscosity extrapolated at near $0 \mathrm{~s}^{-1}$ (in $\mathrm{Pa} \cdot \mathrm{s}$ ), $\eta_{\infty}$ is the viscosity at very high shear rate (in $\mathrm{Pa} \cdot \mathrm{s}$ ), $\mathrm{K}$ (in s) and $\mathrm{m}$ (dimensionless) are fit constants [12]. Table 2 displays each one of these parameters and the correlation coefficient. As observed the fit to the model is reasonably good with increasing values of viscosity as suspension solid concentration rises. In addition, viscosity is low even at very high shear rate which is essential for the suspension to properly flow through the injector. 
Table 2. Rheological parameters of the suspensions after fitting to the Cross model.

\begin{tabular}{|c|c|c|c|c|c|}
\hline Solid loading (vol.\%) & $\boldsymbol{\eta}_{\mathbf{0}} \mathbf{( \mathbf { m P a } \cdot \mathbf { s } )}$ & $\boldsymbol{\eta} \mathbf{( \mathbf { m P a } \cdot \mathbf { s } )}$ & $\mathbf{K} \mathbf{( s )}$ & $\mathbf{m}$ & $\mathbf{R}^{\mathbf{2}}$ \\
\hline $\mathbf{1 0}$ & 62.9 & 4.9 & 0.098 & 2.12 & 0.98 \\
\hline $\mathbf{1 5}$ & 62.1 & 5.4 & 0.106 & 2.09 & 0.96 \\
\hline $\mathbf{2 0}$ & 100.5 & 6.6 & 0.172 & 1.86 & 0.96 \\
\hline $\mathbf{3 0}$ & 113.0 & 8.6 & 0.166 & 1.20 & 0.96 \\
\hline
\end{tabular}

As also observed in Fig.2 thixotropy values calculated as the area enclosed in the hysteresis loop in flow curves are also low [19,20]; therefore, suspension rheological behaviour keeps practically invariable after rest time or agitation. Consequently, sprayable suspensions up to $30 \mathrm{vol}$ \% can be obtained following the preparation route set out above.

The pressure loss in the injector can be estimated using the following equations:

$$
\begin{aligned}
& \Delta P=1 / 2 \rho K v^{2} \\
& v=\frac{Q}{A}=\frac{4 Q}{\pi D^{2}}
\end{aligned}
$$

where $\Delta \mathrm{P}$ is the pressure loss (in $\mathrm{Pa}$ ), $\rho$ is the suspension density $\left(\mathrm{kg} / \mathrm{m}^{3}\right), \mathrm{K}$ is the pressure loss constant which is dependent on injector geometry and suspension characteristics, $v$ is the injection velocity $(\mathrm{m} / \mathrm{s}), \mathrm{Q}$ is the volumetric flow rate $\left(\mathrm{m}^{3} / \mathrm{s}\right)$ and $\mathrm{D}$ is the injector diameter $(\mathrm{m})$. From these equations, it can be deduced that the relationship between pressure loss and injector diameter follows a fourth power equation. Low viscosity and thixotropy allows suspensions with a solid loading up to 20 vol.\% to easily flow through a $150 \mu \mathrm{m}$ injector in spite of the high pressure loss of this component. Unfortunately, suspension density and viscosity inevitably increase at higher solid loading and therefore pressure loss also rises. For this reason, 30 vol.\% suspension becomes unsprayable with the system used in the present work (maximum pressure of $6 \mathrm{bar})$ and an injector diameter change (200 $\mu \mathrm{m}$ instead of $150 \mu \mathrm{m})$ would be necessary. In spite of this limitation suspensions with a solid loading significantly higher than those reported in previous works can be injected. It is an important achievement because, as explained above in the introduction section, an increase of the suspension solids content involves energy saving and consequently an easier industrial scaling $[9,10,14,15]$.

On the other hand, ageing effect is also an important phenomenon taking place when handling suspensions. Ceramic suspensions usually display an ageing or change of their rheological behaviour with time, specifically in very concentrated suspensions [19]. This certainly represents a problem at a potential industrial scale since suspensions feedstocks should be used immediately after their preparation. However, the ageing problem can be reduced or minimised if the suspension formulation is optimised. In this case, as observed in Fig. 3 there is no ageing within 7 days for the 30 vol.\% suspension whose viscosity and thixotropy values practically keep constant within measurement 
errors (4\% error in the torque apparatus, but higher systematic errors up to $10 \%$ are possible due to experimental variations in the preparation of the suspension).

\subsection{SPS deposition}

\subsubsection{Coatings from suspensions up to $20 \mathrm{vol} . \%$}

Coatings with different solid loadings (10, 15 and 20 vol.\%) were deposited by SPS using different spraying distances (30, 40 and $50 \mathrm{~mm}$ ). In addition, $30 \mathrm{vol} \%$ suspension was also deposited using other spraying distances (50 and $60 \mathrm{~mm}$ ) because of sprayability reasons, as explained below. All coatings display a two-zone microstructure, as revealed in Fig. 4. This kind of microstructure, common in SPS coatings as reported in previous papers, consists in partially melted (PM) zones surrounded by a fully melted (FM) matrix $[6,21]$. The reason for this microstructure relates to the fact that a high amount of plasma power is used to evaporate the liquid, resulting in particles or agglomerates, which were just partially melted and then embedded by the completely melted solid. Using water as liquid feedstock instead of ethanol causes higher power requeriments giving rise to lower melting. Besides the presence of partially melted zones, a low solid melting degree results in a high coating porosity which can contribute to reduce thermal conductivity and improve the thermal fatigue resistance while coating hardness can be impaired [3,8]. Furthermore the higher surface tension of water with respect to ethanol also favours that the liquid drops, which are formed inside the plasma plume after suspension stream fragmentation, become larger making the heat transmission even more difficult.

Chemical elements distribution in the coatings were analysed by EDX microanalysis. As an example Fig. 5 displays an element mapping of coating obtained from 10 vol.\% suspension at $40 \mathrm{~mm}$. These element mappings confirm that $\mathrm{Al}_{2} \mathrm{O}_{3}$ and $\mathrm{ZrO}_{2}$ appear homogeneously distributed throughout the coating. In addition, the $\mathrm{Al}_{2} \mathrm{O}_{3}: \mathrm{ZrO}_{2}$ ratio lies close to the desirable value ( $60 \mathrm{wt} \%$ and $40 \mathrm{wt} \%$ respectivlely) in all coatings.

Regarding the crystalline phases, all coatings display a similar XRD pattern. As another example, an XRD pattern of the coating prepared from 15 vol.\% suspension obtained at $40 \mathrm{~mm}$ is shown in Fig. 6. It can be appreciated that coatings were mainly crystalline with $\alpha-\mathrm{Al}_{2} \mathrm{O}_{3}$ and metastable t'- $\mathrm{ZrO}_{2}$ as main phases. $\gamma-\mathrm{Al}_{2} \mathrm{O}_{3}$, usual in $\mathrm{Al}_{2} \mathrm{O}_{3}$ and $\mathrm{Al}_{2} \mathrm{O}_{3} / \mathrm{YSZ}$ coatings, was not observed due probably to two different reasons: unmelted regions kept the crystalline phases of the starting powders while an overheating of the coating together with the reheating of the coating by the subsequent deposition passes can explain the phase transformation from metastable $\gamma$ - to $\alpha-\mathrm{Al}_{2} \mathrm{O}_{3}$ in the melted zones [17]. Nevertheless these observed phases in the coatings are characterised by high thermal stability in a wide range of temperatures which include those of operational turbines [2], In addition, melted $\alpha-\mathrm{Al}_{2} \mathrm{O}_{3}$ and t'- $\mathrm{ZrO}_{2}$ display better mechanical properties than those exhibited by the other possible crystalline phases [17].

In spite of the similarities among the coatings, differences between them can also be observed so that it can be concluded that suspension characteristics as well as spraying parameters have a marked influence on the coatings. 30 vol.\% coatings are discussed later because they were obtained using a different injector and therefore results are not directly comparable. Coatings porosity, thickness and microhardness values are jointly plotted in Fig. 7 in order to better detect the differences between coatings. On the one hand, the coatings were thicker at higher solids loadings because the amount of solid 
deposited per spraying pass augmented. This concentration increase implies energy and time savings and, consequently, an efficiency improvement in the technique. On the other hand, coatings become more porous when the suspension solids loading increased. A plausible explanation can be related to the fact that higher viscosity suspensions obtained from more concentrated suspensions give rise to larger drops which make the heat transport more difficult, as set out in previous works[5,21]. Nevertheless this higher porosity values in the coatings do not impair coating hardness. This is because unmelted areas of SPS coatings become denser when suspension concentration increases, as it can be observed in Fig. 8. As most of the porosity is located inside the unmelted areas; coatings containing more unmelted zones displayed more porosity. However, the pores inside unmelted zones are expected to be finer when these zones display a denser aspect and, consequently, mechanical and thermal properties can be improved in some extent [22].

In addition to the starting suspension characteristics, spraying distance also influences on coating properties. However, both effects cannot be discussed separately. The optimum distance for minimizing porosity is found when the liquid evaporates and the solid melts but a resolidification is avoided. In the case of 10 and 15 vol.\% suspensions, the optimum distance was $40 \mathrm{~mm}$. However, for the 20 vol.\% suspension, the optimal distance was $30 \mathrm{~mm}$ because the evaporation process becomes faster and less residence time inside the plasma plume is necessary. On the contrary with more diluted suspensions, a longer residence time and, consequently, a greater spraying distance are necessary to evaporate the liquid and then to completely melt the solid. Regarding the mechanical properties, microhardness increases when the porosity decreases only if coatings produced with the same suspension are compared because under these circumstances porosity decreases without significant change in pore size [22].

\subsubsection{Coatings from suspensions at 30 vol.\%}

Highly concentrated suspensions (30 vol.\%) were also deposited, as mentioned in section 3.1. It is important to note that injection phenomenon changed respect the previous depositions because the injector diameter increased from $150 \mu \mathrm{m}$ to $200 \mu \mathrm{m}$. The suspension injection properly occurs when the suspension kinetic power (liquid) overcomes the plasma kinetic energy (gas):

$$
\rho_{l} v_{l}^{2}>\rho_{g} v_{g}^{2}
$$

where $\rho$ is the density $\left(\mathrm{kg} / \mathrm{m}^{3}\right)$, $\mathrm{v}$ is the velocity $(\mathrm{m} / \mathrm{s})$ while $\mathrm{l}$ and $\mathrm{g}$ subscripts refer to suspension and plasmogen gas respectively. According to equation 3, injection velocity decreases when injector diameter grows and therefore, the suspension kinetic energy lowers. It implies that suspension cannot penetrate into the plasma core and the heat energy transmission from plasma to suspension becomes more difficult resulting in incomplete solid melting. One possibility to enhance the injection is to raise the suspension flow rate. However, this fact causes a higher power requirement to evaporate more amount of liquid and to melt the solid. A high power plasma torch would be therefore required to cope with this additional energy need (i.e. a three cathode torch).

The suspension injection modification clearly affected the coating microstructure and properties. Thus, despite the fact that coatings from 30 vol.\% suspension also displayed 
a bimodal microstructure, as seen in Fig. 9. More porous and unmelted zones can be observed when compared to the other coatings obtained from less concentrated feedstock suspensions. The reason for this high porosity, which is confirmed by porosity values in Fig 6, can be due to an incomplete melting caused by an inadequate injection of the suspension inside the plasma plume. Owing to less melting, the spraying efficiency became poorer and the coatings displayed a smaller thickness despite the amount of solid per spraying pass was even higher.

In addition to microstructural differences, it was also observed that coatings with a spraying distance below $40 \mathrm{~mm}$ were not suitable owing to overheating of the samples. The reason deals with the fact that an important fraction of plasma energy is not used to heat the material; therefore this energy is supplied directly to the samples. Hence, spraying distances of 50 and $60 \mathrm{~mm}$ for the 30 vol.\% suspension were addressed. As observed in Fig. 7 both coatings displayed similar porosity and microhardness values although the $60 \mathrm{~mm}$ coating was more porous and softer than the coatings obtained with shorter spraying distance. It is probable that a lower spraying distance would be more favourable to coating performance if the overheating of the sample or the inadequate injection was solved. In conclusion, it becomes evident again that a high power plasma torch or SPS system with more pressure is needed to spray very concentrated suspensions. Nevertheless, the present work demonstrates that concentration suspensions as high as $30 \mathrm{vol} . \%$ can be prepared as well as deposited by SPS whenever an adequate colloidal characterisation and rheological adjustment of the suspension is carried out.

\section{Conclusions}

An optimisation of the amount of dispersant with the aim of preparing stable and welldispersed concentrated suspensions for SPS process was carried out by colloidal characterisation of the starting particles $\left(\mathrm{Al}_{2} \mathrm{O}_{3} / \mathrm{ZrO}_{2}\right)$. Then, a rheological study was performed measuring the viscosity and thixotropy of suspensions with different solids loadings. This part of the research is essential to know if the suspensions are sprayable, as well as to predict the suspension injection process.

Coatings from aqueous, highly concentrated suspensions of $60 / 40$ wt $\% \mathrm{Al}_{2} \mathrm{O}_{3} / \mathrm{ZrO}_{2}$ particles were successfully performed by SPS technique at different spraying distances. Suspension concentration ranged from 10 to 30 vol.\%. It was that the optimal spraying distance becomes shorter when the suspension solids loading increases due to the less amount of solvent to evaporate therefore shorter residence time inside the plasma plume is necessary. On the other hand, coatings from more concentrated suspensions displayed higher amounts of unmelted zones. However, microhardness of coatings resulting from these more concentrated suspensions was not impaired because of the presence of denser unmelted zones.

One of the most important goals achieved in the present research was to succeed in preparing and then depositing highly concentrated suspensions (30 vol.\% solid loading reached for the first time) by SPS technique. This suspension feedstock is quite more concentrated than others addressed in previous works. Besides liquid used was water instead of ethanol which is much more preferred due to economical, environmental, and safety reasons. Nevertheless, the suspension injection for the highest concentration 
suspension was not completely satisfactory owing to the limitations of the used SPS system. These constrains could be solved by using a SPS system with a higher propulsion pressure or a high power plasma torch. In conlusion, this preliminary work can be useful to establish the basis for obtaining coatings from aqueous and very concentrated suspensions which can result in an enhancement of industrial scalability.

\section{Acknowledgments}

This work has been supported by the Spanish Ministry of Economy and Competitiveness, MINECO, (project MAT2015-67586-C3-R). M.D. Salvador thanks to CAPES - Programa Ciências sem Fronteiras (Brazil) for the concession of a PVE project No A086/2013. A. Borrell acknowledges the MINECO for her Juan de la CiervaIncorporación contract (IJCI-2014-19839) and the Program to Support Research and Development (PAID-00-15) of the Universitat Politècnica de València. 


\section{Reference}

[1] D.R. Clarke, M. Oechsner, N.P. Padture, Thermal-barrier coatings for more efficient gas-turbine engines, MRS Bull. 37 (2012) 891-898.

[2] T. Inoue, S. Sodeoka, M. Suzuki, Thermal Stability and Mechanical Properties of Plasma Sprayed Al2O3/ZrO2 Nano-Composite Coating, in: Sci. Eng. Ceram. III, Trans Tech Publications, 2006: pp. 513-516.

[3] F. Tarasi, M. Medraj, A. Dolatabadi, J. Oberste-Berghaus, C. Moreau, Effective parameters in axial injection suspension plasma spray process of aluminazirconia ceramics, J. Therm. Spray Technol. 17 (2008) 685-691.

[4] R. Vassen, A. Stuke, D. Stöver, Recent developments in the field of thermal barrier coatings, in: J. Therm. Spray Technol., 2009: pp. 181-186.

[5] P. Fauchais, G. Montavon, R.S. Lima, B.R. Marple, Engineering a new class of thermal spray nano-based microstructures from agglomerated nanostructured particles, suspensions and solutions: an invited review, J. Phys. D. Appl. Phys. 44 (2011) 093001.

[6] L. Pawlowski, Suspension and solution thermal spray coatings, Surf. Coatings Technol. 203 (2009) 2807-2829.

[7] H. Kassner, R. Siegert, D. Hathiramani, R. Vassen, D. Stoever, Application of suspension plasma spraying (SPS) for manufacture of ceramic coatings, J. Therm. Spray Technol. 17 (2008) 115-123.

[8] P. Carpio, Q. Blochet, B. Pateyron, L. Pawłowski, M.D. Salvador, A. Borrell, et al., Correlation of thermal conductivity of suspension plasma sprayed yttria stabilized zirconia coatings with some microstructural effects, Mater. Lett. 107 (2013) 370-373.

[9] P. Fauchais, M. Vardelle, A. Vardelle, S. Goutier, What Do We Know, What are the Current Limitations of Suspension Plasma Spraying?, J. Therm. Spray Technol. 24 (2015) 1120-1129.

[10] F.L. Toma, A. Potthoff, L.M. Berger, C. Leyens, Demands, Potentials, and Economic Aspects of Thermal Spraying with Suspensions: A Critical Review, J. Therm. Spray Technol. 24 (2015) 1143-1152.

[11] M. Vicent, E. Bannier, P. Carpio, E. Rayón, R. Benavente, M.D. Salvador, et al., Effect of the initial particle size distribution on the properties of suspension plasma sprayed Al2O3-TiO2 coatings, Surf. Coatings Technol. 268 (2015) 209215.

[12] C. A. Gutierrez, R. Moreno, Interparticle potentials in nonaqueous silicon nitride suspensions, J. Am. Ceram. Soc. 86 (2003) 59-64.

[13] K. VanEvery, M.J.M. Krane, R.W. Trice, Parametric study of suspension plasma spray processing parameters on coating microstructures manufactured from nanoscale yttria-stabilized zirconia, Surf. Coatings Technol. 206 (2012) 24642473.

[14] R. Rampon, C. Filiatre, G. Bertrand, Suspension plasma spraying of YPSZ coatings: Suspension atomization and injection, J. Therm. Spray Technol. 17 (2008) 105-114.

[15] D. Waldbillig, O. Kesler, The effect of solids and dispersant loadings on the suspension viscosities and deposition rates of suspension plasma sprayed YSZ coatings, Surf. Coatings Technol. 203 (2009) 2098-2101.

[16] X. Song, T. Suhonen, T. Varis, L. Huang, X. Zheng, Y. Zeng, Fabrication and Characterization of Amorphous Alumina-Yttria-Stabilized Zirconia Coatings by Air Plasma Spraying, J. Therm. Spray Technol. 23 (2014) 1302-1311. 
[17] F. Tarasi, M. Medraj, A. Dolatabadi, J. Oberste-Berghaus, C. Moreau, Phase formation and transformation in alumina/YSZ nanocomposite coating deposited by suspension plasma spray process, in: J. Therm. Spray Technol., 2010: pp. 787-795.

[18] P. Carpio, R. Moreno, A. Gómez, M.D. Salvador, E. Sánchez, Role of suspension preparation in the spray drying process to obtain nano/submicrostructured YSZ powders for atmospheric plasma spraying, J. Eur. Ceram. Soc. 35 (2015) 237247.

[19] T. Molina, M. Vicent, E. Sánchez, R. Moreno, Dispersion and reaction sintering of alumina-titania mixtures, Mater. Res. Bull. 47 (2012) 2469-2474.

[20] C.A. Gutiérrez, R. Moreno, Preventing ageing on Al2O3 casting slips dispersed with polyelectrolytes, J. Mater. Sci. 35 (2000) 5867-5872.

[21] P. Carpio, E. Bannier, M.D. Salvador, A. Borrell, R. Moreno, E. Sánchez, Effect of particle size distribution of suspension feedstock on the microstructure and mechanical properties of suspension plasma spraying YSZ coatings, Surf. Coatings Technol. 268 (2015) 293-297.

[22] A. Bacciochini, F. Ben-Ettouil, E. Brousse, J. Ilavsky, G. Montavon, A. Denoirjean, et al., Quantification of void networks of as-sprayed and annealed nanostructured yttria-stabilized zirconia (YSZ) deposits manufactured by suspension plasma spraying, Surf. Coatings Technol. 205 (2010) 683-689. 


\section{Figure caption}

Figure 1. Zeta potential curves of $\mathrm{Al}_{2} \mathrm{O}_{3}$ and $\mathrm{Y}-\mathrm{TZP}$ as a function of $\mathrm{pH}$ with and without dispersant.

Figure 2. Flow curves of suspensions with different solids loadings.

Figure 3. Ageing effect on the rheological behaviour of 30 vol.\% suspension.

Figure 4. Cross-section micrographs of coatings obtained from suspensions with different solids loadings (10, 15 and $20 \mathrm{vol} . \%)$ at different spraying distances (30, 40 and $50 \mathrm{~mm}$ ). Fully-melted zones (FM) and partially-melted zones (PM) are marked.

Figure 5. Element mapping of coating obtained from 10 vol. \% at $40 \mathrm{~mm}$.

Figure 6. XRD pattern of coating obtained from 15 vol.\% suspension at $40 \mathrm{~mm}$.

Figure 7. Thickness, porosity and microhardness of the different coatings.

Figure 8. Detail of unmelted areas of coatings obtained with different solid loadings.

Figure 9. Cross section micrograph of coating obtained from 30 vol.\% suspension and details of unmelted zones. 
Figure list

Figure 1

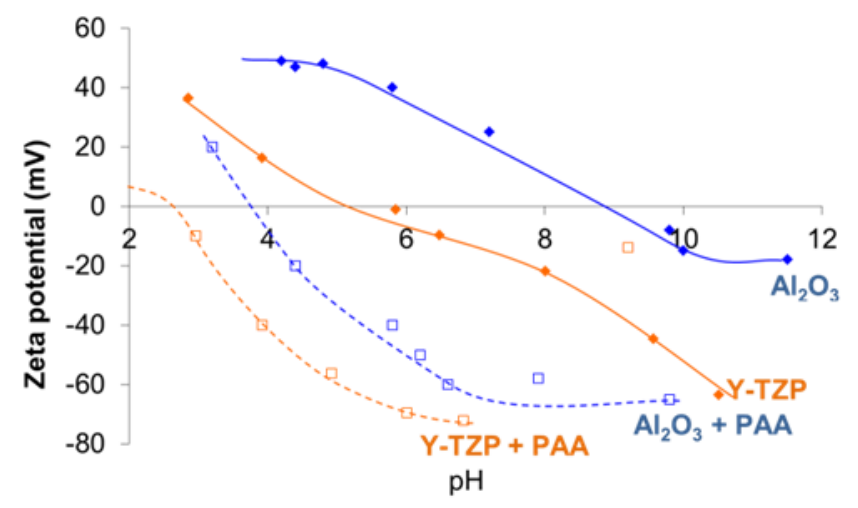

Figure 2

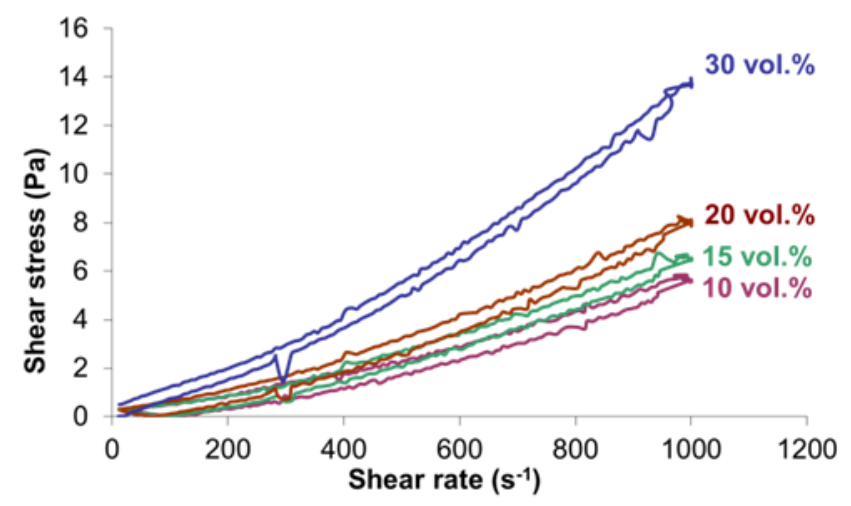

Figure 3

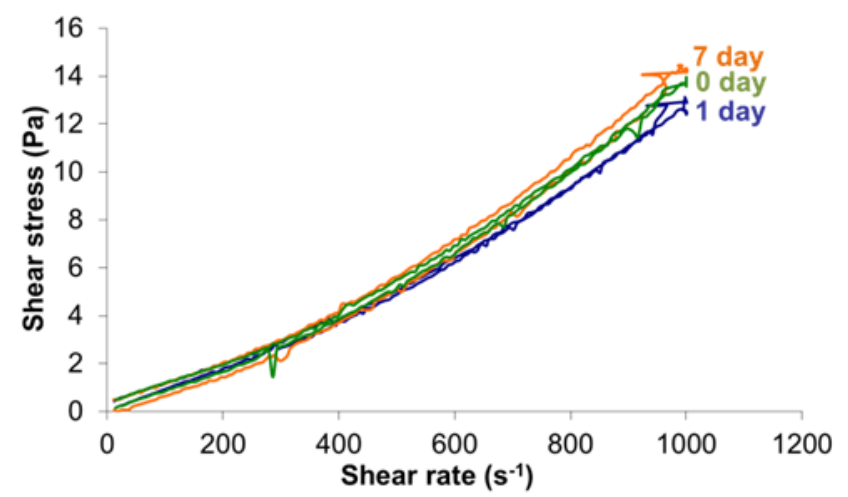


Figure 4

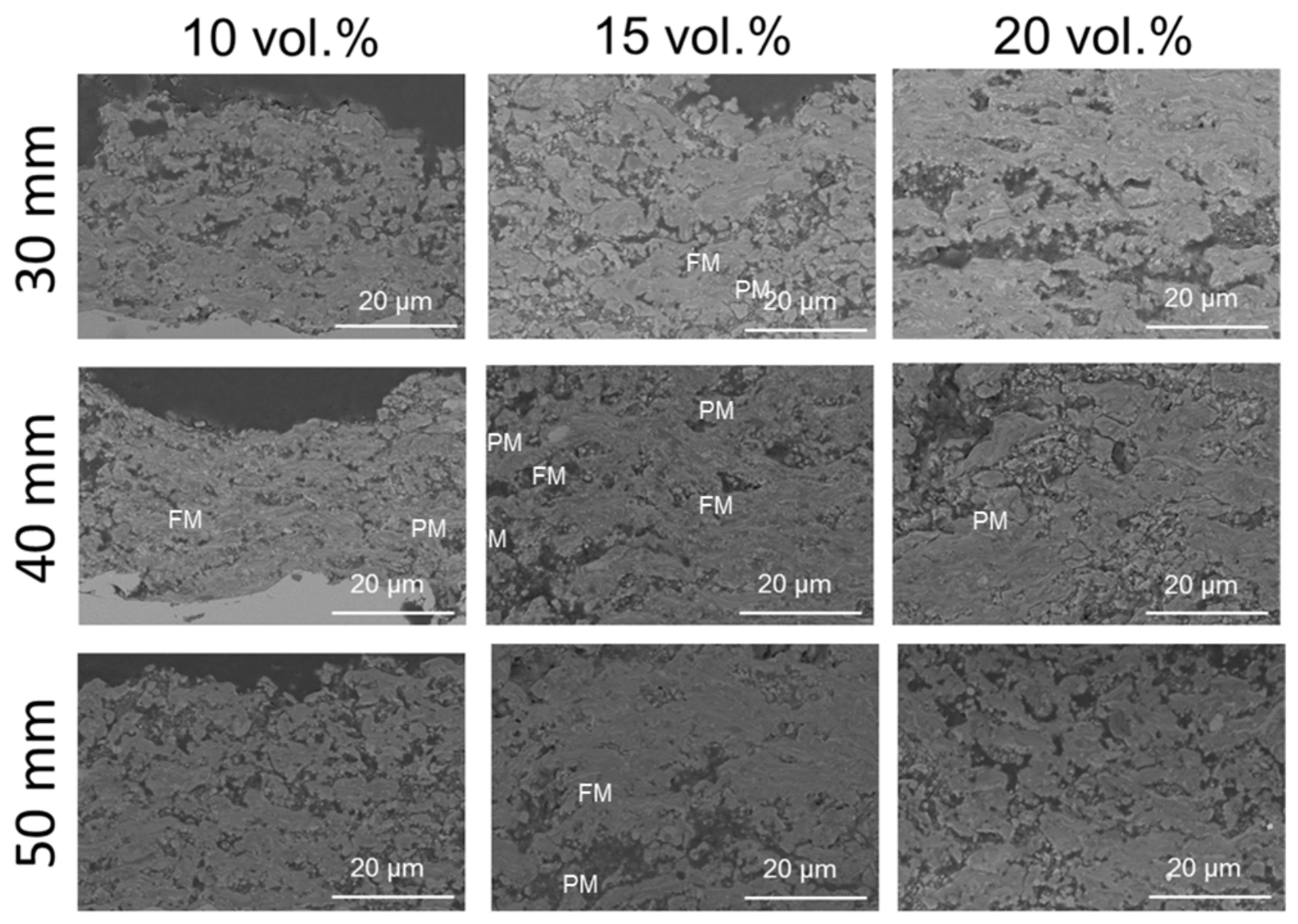

Figure 5

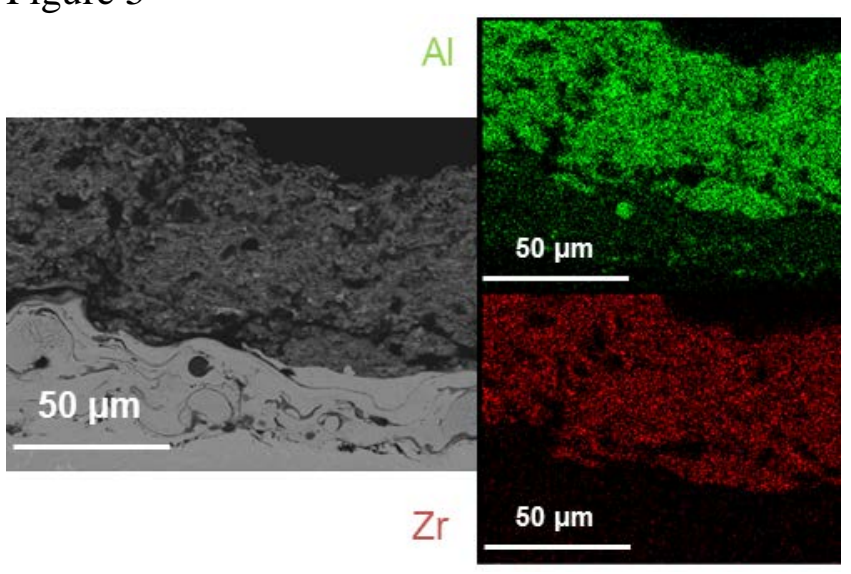

Figure 6

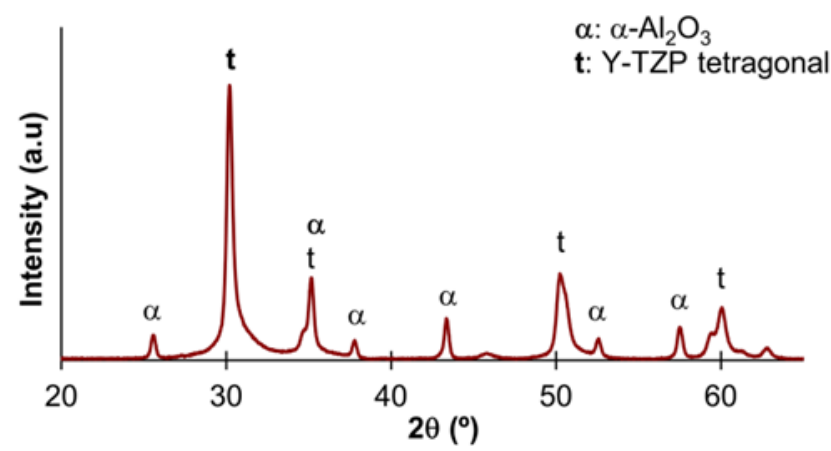


Figure 7
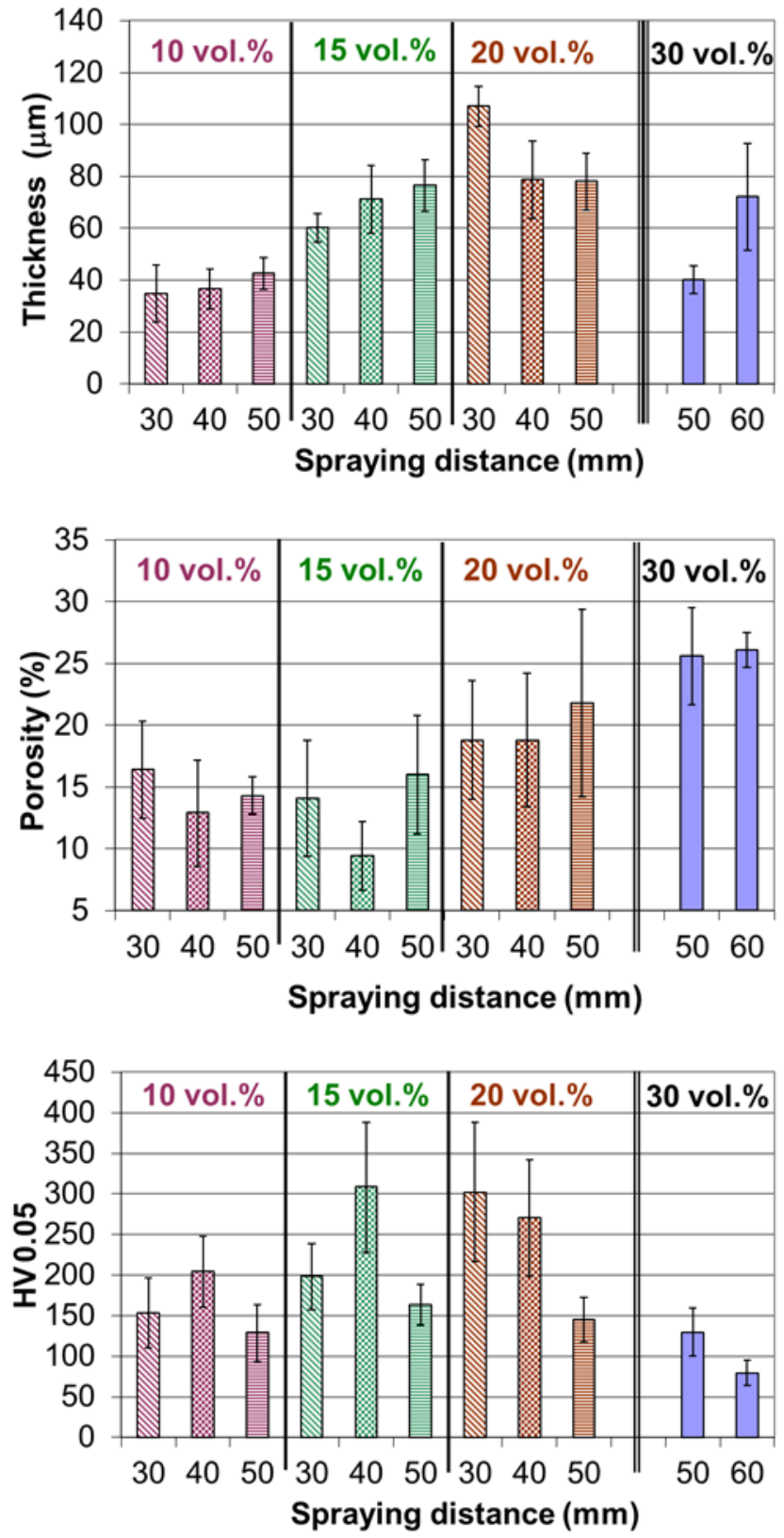

Figure 8
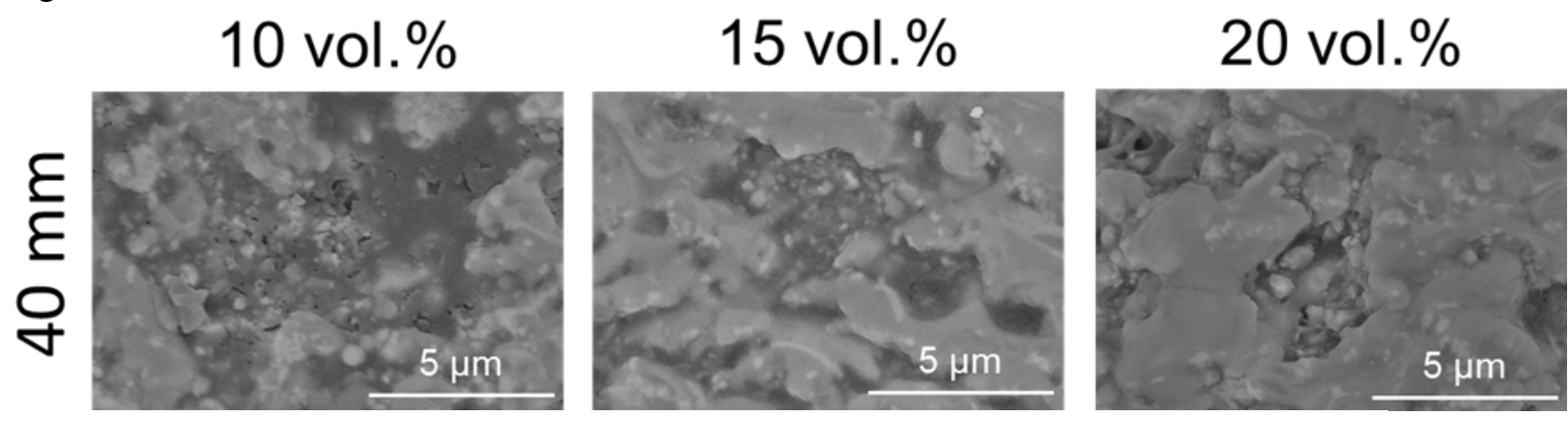
Figure 9

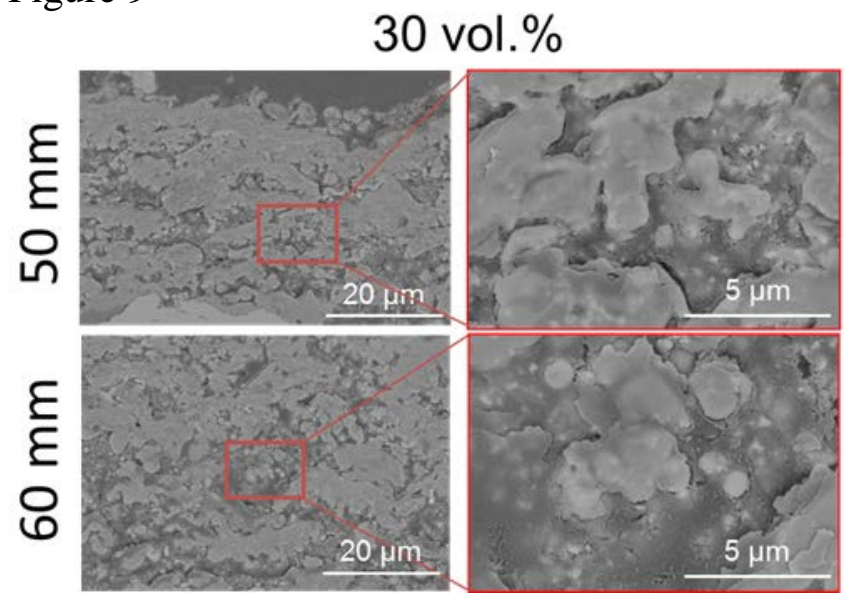

